\title{
sciendo
}

Folia Oeconomica Stetinensia

Volume 20 (2020) Issue 1

DOI: $10.2478 /$ foli-2020-0019
WYDZIAL NAUK EKONOMICZNYCH I ZARZA¿DZANIA

\section{CLUSTERING POLAND AMONG EU COUNTRIES IN TERMS \\ OF A SUSTAINABLE DEVELOPMENT LEVEL IN THE LIGHT \\ OF VARIOUS CLUSTER STABILITY MEASURES}

Dorota Rozmus, Ph.D.

University of Economics in Katowice

College of Finance

Department of Economic and Financial Analysis

1 Maja 50, 40-287 Katowice, Poland

e-mail:dorota.rozmus@ue.katowice.pl

ORCID: 0000-0002-0565-5319

Received 21 October 2019, Accepted 21 March 2020

\begin{abstract}
Research background: Recently in the context of taxonomy methods a lot of attention has been paid to the issue of stability of these methods, i.e. the answer to the question: do the groups that were created as a result of clustering really occur (the structure is stable), or did they appear accidentally.

Purpose: The article is inspired by the Reviewers of the author's previous publications on this subject and will be a summary of research to date which has followed two paths. On one hand, they recognize ways of measuring cluster stability proposed in the literature (e.g. Rozmus, 2017). On the other, they use these measures to cluster Poland among the EU members in terms of sustainable development level (e.g. Rozmus, 2019).

Research methodology: The literature proposes a number of different ways for measuring stability. Theoretical considerations have also led to the development of computer tools for the practical implementation of the proposed ways to study stability. The practical tools are available within several $\mathbf{R}$ packages, e.g.: clv, clValid, fpc, which are used in this research

Results: The results, however, showed that different measures of stability lead to different results.

Novelty: The innovation of this approach is the use of stability measures to such a problem (i.e. clustering EU members in terms of the sustainable development level). In addition, the article will report a synthesis and comparative analysis of the results obtained using various stability measures.
\end{abstract}

Keyword: clustering, taxonomy, stability, sustainable development

JEL classification: $\mathrm{C} 38$ 


\section{Introduction}

The main problem in taxonomy is to determine whether the groups that we received reflect the actual structure of the groups present in the data. This involves the problem of selecting a "clustering model", e.g.: the number of groups $k$, a distance metric, the control parameters of an algorithm. Recently, the stability criterion is increasingly gaining in popularity in response to these problems.

Informally, this criterion states that if a cluster algorithm is repeatedly used for independent samples (with unchanged parameters of the algorithm), resulting in similar grouping results, it can be considered as stable and reflecting the actual structure of the groups (Shamir, Tishby, 2008). Z. Volkovich, Z. Barzily, D. Toledano-Kitai and R. Avros (2010) even state that the number of groups that maximizes the stability of clustering can serve as an estimate of the "true" number of groups.

The literature proposes a number of different ways for measuring stability (e.g., BenHur, Guyon, 2003; Brock, Pihur, Datta, Datta, 2008; Henning, 2007; Fang, Wang, 2012; Lord, Willems, Lapointe, Makarenkov, 2017; Marino, Presti, 2019; Suzuki, Shimodaira, 2006). Theoretical considerations have also led to the development of computer tools for the practical implementation of the proposed ways to study stability. The practical tools are available within several R packages, for example: clv, clValid, clusterstability, fpc, pvclust.

Due to the hypothesis that cluster stability can be an answer to the question about the right number of groups in clustering, the purpose of the paper will be to examine the stability of grouping EU countries in terms of sustainable development level. Special attention will be devoted to Poland's place among EU countries in this respect. The choice of such a research objective is dictated by the fact that the study of the similarity of territorial units in different aspects (e.g. level of economic development, standard of living of the population) is subject to a number of scientific papers, articles and reports (e.g. Kronthaler, 2005; Repkine, 2012; Shubat, Bagirova, Makhabat, Ivlev, 2016; Simpach, 2013). Little attention is devoted to the study of the stability of obtained solutions.

The main hypothesis is that since different ways of measuring cluster stability really do the same thing, i.e. examine the existence of a specific structure in the data, we should get similar clustering results, regardless of the chosen method. This hypothesis will be verified in this study. 


\section{Measures of cluster stability}

This part of the article presents the research methods, i.e. cluster stability measures. In this study only such stability measures that one can find in the $\mathbf{R}$ program were used, i.e. measures from packages: clv, clValid and fpc. There are many more packages for stability testing of course, but those mentioned libraries can be used with various clustering methods, e.g. $k$-means, $k$-medoids, hierarchical and others.

\subsection{A. Ben-Hur and I. Guyon stability measure (clv package)}

The concept of stability by A. Ben-Hur and I. Guyon (2003) is based on the finding that if the clustering properly represents the structure in the data, it should be stable with respect to small changes in the data set. They proposed two measures of stability: a measure based on the index of similarity between two partitions (implemented by the function cls.stab. sim. ind) and a measure based on the pattern-wise agreement concept (function cls.stab. opt.assign).

The algorithm of calculating the stability measure based on the index of similarity between two partitions (cls.stab.sim. ind function in R) can be described in the following steps:

1. Cluster the original data set in order to obtain the reference partition.

2. Select a random subsample of observations from the original data set and group the objects from this subsample.

3. Calculate the stability between the reference partition and the partition of the subsample using the index of similarity between two partitions (e.g. Rand index).

4. Repeat the procedure several times.

5. Repeat the procedure for different values of $k$ (number of groups).

The measure based on the pattern-wise agreement concept (cls.stab.opt.assign function in R) is based on the idea of pattern-wise agreement and pattern-wise stability.

Given two groupings $L_{1}$ and $L_{2}$, pattern-wise agreement can be defined as follows:

$$
\delta_{\sigma}(i)=\left\{\begin{array}{lll}
1, & \text { if } & \sigma\left(L_{1}(i)\right)=L_{2}(i) \\
0, & \text { if } & \sigma\left(L_{1}(i)\right) \neq L_{2}(i)
\end{array}\right.
$$

where: $\sigma:\left\{1, \ldots, k_{1}\right\} \rightarrow\left\{1, \ldots, k_{2}\right\}$. 
Pattern-wise stability is defined as the fraction of subsampled partitions where the subsampled labeling of pattern $i$ agrees with that of the reference labeling, by averaging the pattern-wise agreement:

$$
n(i)=\frac{1}{N_{i}} \sum \delta_{\sigma}(i)
$$

where $N_{i}$ - number of subsamples where pattern $i$ appears.

The stability of group $j$ in the reference partition is the average of pattern-wise stability:

$$
c(j)=\frac{1}{\left|L_{1}=j\right|} \sum_{i \in\left(L_{1}=j\right)} n(i)
$$

The stability of the reference partition into $k$ groups is defined as:

$$
S_{k}=\min _{j} c(j)
$$

Finally the most stable clustering is indicated by the maximum of $S_{k}$.

\subsection{G. Brock, Pihur, Datta and Datta stability measure (clValid package)}

Measures of stability by G. Brock et al. can be found in the clValid package. The Authors' measures are dedicated mainly for validating the results of clustering analysis in biology. There are three main types of cluster validation measures available: "internal", "biological" and "stability".

The article focuses only on the last group of measures. They evaluate the stability of a clustering result by comparing it with the clusters obtained by removing one column (i.e. variable) at a time (Brock et al., 2008). These measures include: the average proportion of nonoverlap (APN), the average distance (AD), the average distance between means (ADM), and the figure of merit (FOM).

Only APN was used in the experiments because this is the only measure that is normalized in the interval $(0,1)$, with values close to zero corresponding with highly consistent clustering results. APN measures the average proportion of observations not placed in the same cluster by clustering based on the full data and clustering based on the data with a single column removed:

$$
A P N=\frac{1}{M \cdot N} \sum_{i=1}^{N} \sum_{j=1}^{M}\left(1-\frac{n\left(c^{i, j} \cap c^{i, 0}\right)}{n\left(c^{i, 0}\right)}\right)
$$


where:

$c^{i, 0} \quad$ - represents the cluster containing observation $i$ using the original clustering (based on all available data),

$c^{i, j}$ - represents the cluster containing observation $i$ where the clustering is based on the data set with $j$ column removed,

$n(\cdot)$ - is the cardinality of a cluster,

$N$ - denotes the total number of observations (rows) in a data set,

$M$ - denotes the total number of variables (columns) in a data set.

\subsection{Y. Fang and J. Wang stability measure (fpc package)}

The Y. Fang and J. Wang stability measure (2012) can be found in fpc package and it includes two functions for measuring stability: clusterboot and nselectboot. In the experiments only the nselectboot function was used.

The authors focus on the concept of stability as robustness to randomness present in the sample. Drawing on the work of J. Wang (2010), they formulate the concept of stability in the following way: if one draws samples from the population and applies a selected clustering algorithm, the results of grouping should not be very different.

The presented Y. Fang and J. Wang measure is based on the following general idea: several times two bootstrap samples are drawn from the data and the number of clusters is chosen by optimising an instability estimation from these pairs.

Denoting a cluster algorithm with $k \geq 2$ groups by $\Psi(\cdot, k)$, when we use it to sample $X^{n}$ we get the clustering $\Psi_{X^{n}, k}(x)$; the algorithm can be presented according to the following procedure. For the assumed value of $k=2, \ldots, K$ :

1. Construct $B$ independent pairs of bootstrap samples $\left(X_{b}^{n^{*}}, \tilde{X}_{b}^{n^{*}}\right), b=1, \ldots, B$.

2. Make groupings $\Psi_{X_{b}^{n *}, k}$ and $\Psi_{\tilde{X}_{b}^{n *}, k}$ on $\left(X_{b}^{n *}, \tilde{X}_{b}^{n *}\right), b=1, \ldots, B$.

3. For each pair $\Psi_{X_{b}^{n *}, k}$ and $\Psi_{\widetilde{X}_{b}^{n *}, k}$ calculate the empirical clustering distance:

$$
d\left(\Psi_{X_{b}^{n^{*}, k}}, \Psi_{\tilde{X}_{b}^{n^{*}, k}}\right)=\frac{1}{n^{2}} \sum_{i=1}^{n} \sum_{j=1}^{n}\left|I\left\{\Psi_{X_{b}^{n^{*}, k}}\left(x_{i}\right)=\Psi_{X_{b}^{n^{*}, k}}\left(x_{j}\right)\right\}-I\left\{\Psi_{\tilde{X}_{b}^{n^{*}}, k}\left(x_{i}\right)=\Psi_{\tilde{X}_{b}^{n^{*}, k}}\left(x_{j}\right)\right\}\right|
$$

4. Instability of clustering is calculated as:

$$
\hat{s}_{B}=\frac{1}{B} \sum_{b=1}^{B} d\left(\Psi_{X_{b}^{n *}, k}, \Psi_{\tilde{X}_{b}^{n *}, k}\right)
$$




\section{A data set and the scheme of research}

A data set was built on the data obtained from the Sustainable Development Indicators Application developed by the Central Statistical Office in Poland. This application monitors the implementation of the sustainable development policy in EU countries. The data are divided into four groups, monitoring the implementation of the sustainable development policy within the following domains:

- social,

- economic,

- environmental,

- institutional-political.

The study used the data from 2015, comprising 19 metric variables in the social domain, 18 variables in the economic domain, 11 in the environmental domain, and 15 in the institutionalpolitical domain (only complete data were used).

Clustering was carried out within each domain separately. This is related to the idea of weak and strong sustainability (Borys, 2005, pp. 41-43, 2011; Lorek, 2011). In accordance with weak sustainability, it is permissible to consider all domains together, because the resources from these domains are considered substitutable. ${ }^{1}$ According to strong sustainability, resources within each domain are considered to be complementary, and therefore every order should be considered separately because it is not possible to develop one domain at the expense of the other. And in this spirit, the analysis presented in the paper was carried out.

As a clustering method, two partitioning algorithms were used, i.e. the $k$-means and $k$-medoids method and two hierarchical algorithms, i.e. group average - link and Ward methods with the Euclidean metric as a measure of distance between objects.

In the A. Ben-Hur and I. Guyon measure of stability, similarity between two partitions were tested with all available in Clv package indices, i.e. Rand, dot product, similarity index and Jaccard.

In the stability measure proposed by Y. Fang and J. Wang (fpc package) 100 bootstrap samples were created. Each new dataset (of the same size as the original) is created by resampling the original dataset with a replacement.

\footnotetext{
1 Previous research taking into account all the domains altogether, the results of which were presented at the SKAD'18 conference, provoked a discussion about the correctness of such an approach, as more and more economists are moving away from the concept of weak sustainability.
} 


\section{Empirical results}

As it was mentioned before, the study was carried within each domain separately. The results are discussed below.

On figures 1-4, 7-10, 14-16 and 19-20 there are the presented values of different stability measures used in the experiments. The measures were calculated only for $k=2, \ldots, 5$. Abbreviations used on those figures are explained in (Table 1). In the last column information about the optimization direction of the criterion is presented.

Table 1. Results of clustering for the partitioning method (social domain)

\begin{tabular}{|l|l|c|}
\hline \multicolumn{1}{|c|}{ Abbreviation } & \multicolumn{1}{|c|}{ Description } & $\begin{array}{c}\text { Optimization } \\
\text { direction }\end{array}$ \\
\hline clv_rand_\# & $\begin{array}{l}\text { A. Ben-Hur and I. Guyon measure of stability, with the Rand similarity index } \\
\text { (implemented by the function cls.stab.sim. ind) }\end{array}$ & Maximization \\
\hline clv_dot.pr_\# & $\begin{array}{l}\text { A. Ben-Hur and I. Guyon measure of stability, with the dot product similarity } \\
\text { index (implemented by the function cls.stab.sim. ind) }\end{array}$ & Maximization \\
\hline clv_sim.ind_\# & $\begin{array}{l}\text { A. Ben-Hur and I. Guyon measure of stability, with the similarity index } \\
\text { (implemented by the function cls. stab.sim. ind) }\end{array}$ & Maximization \\
\hline clv_jaccard_\# & $\begin{array}{l}\text { A. Ben-Hur and I. Guyon measure of stability, with the Jaccard similarity index } \\
\text { (implemented by the function cls. stab.sim. ind) }\end{array}$ & Maximization \\
\hline clv1_\# & $\begin{array}{l}\text { A. Ben-Hur and I. Guyon measure of stability implemented by the function } \\
\text { cls.stab.sim. opt.assigned }\end{array}$ & Maximization \\
\hline clvalid_APN_\# & $\begin{array}{l}\text { Measures of stability by Brock et al. indicated by the average proportion } \\
\text { of non-overlap }\end{array}$ & Minimization \\
\hline fpc_\# & $\begin{array}{l}\text { The Y. Fang and J. Wang stability measure (implemented by the } \\
\text { nselectboot function) }\end{array}$ & Minimization \\
\hline
\end{tabular}

\# denotes number of clusters.

Source: own computations.

\subsection{The social domain}

Looking at the values for different stability measures (figures 1-4) it can be seen that for $k$-means and $k$-medoids the most often three clusters were found by the measures of A. Ben-Hur and I. Guyon. Quite different results for discussed methods can be observed in the case of the G. Brock et al. and Y. Fang and J. Wang measures. For hierarchical methods greater discrepancy can be observed. The A. Ben-Hur and I. Guyon measure, depending on the used cluster similarity index, suggests the validity for 2, 3 or 4 groups. It is also worth noticing the tendency of the Y. Fang and J. Wang measure to suggest the largest number of clusters considered. 


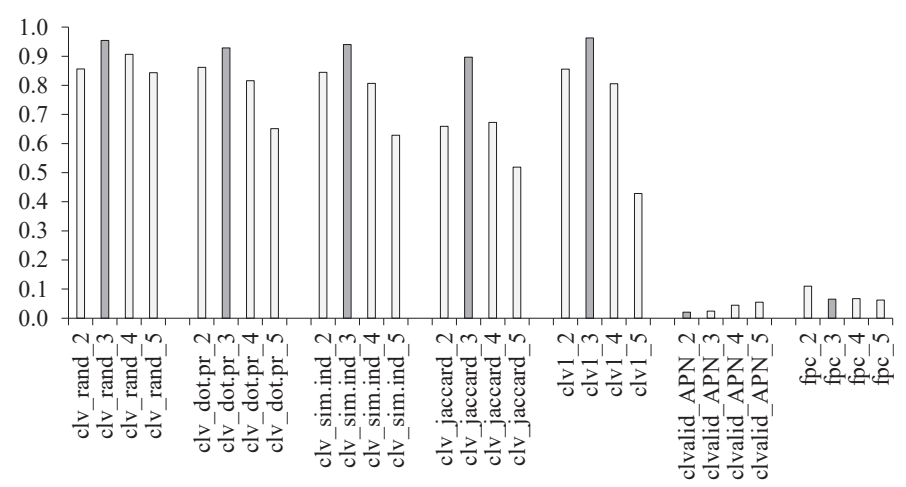

Figure 1. Values of stability measures for the $k$-means method (social domain) Source: own computations.

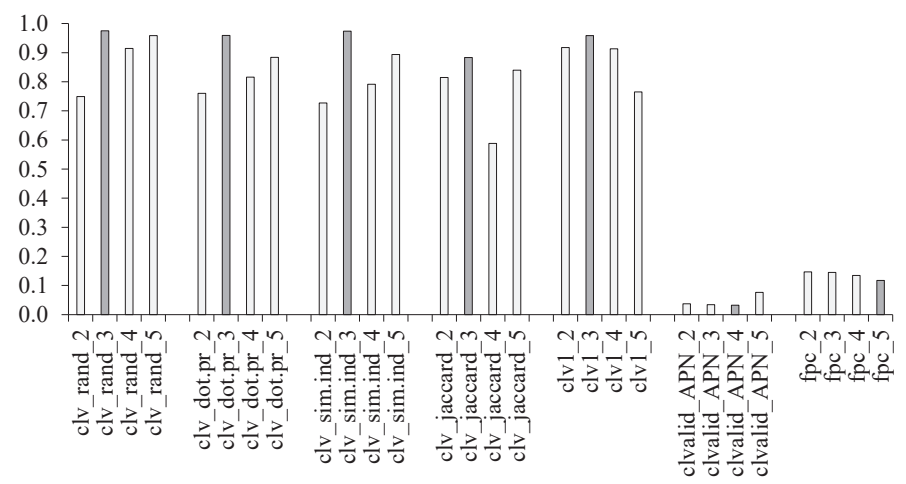

Figure 2. Values of stability measures for the $k$-medoids method (social domain) Source: own computations.

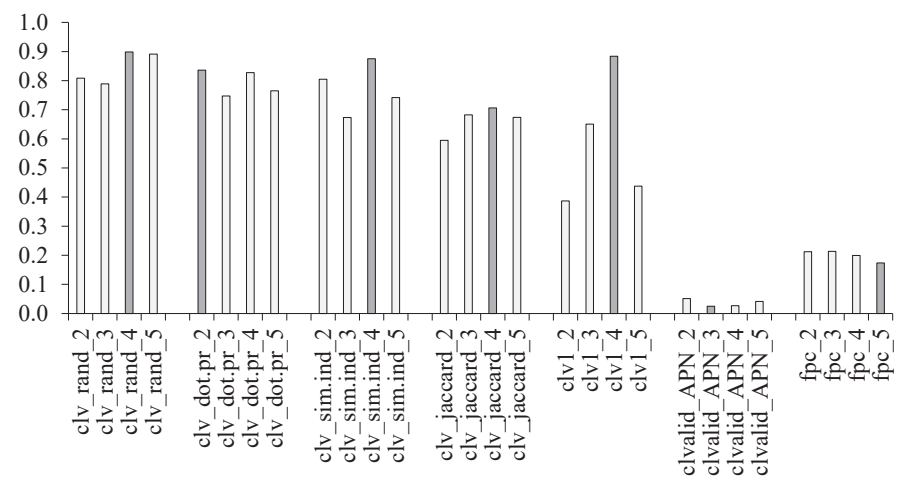

Figure 3. Values of stability measures for the average method (social domain) Source: own computations. 


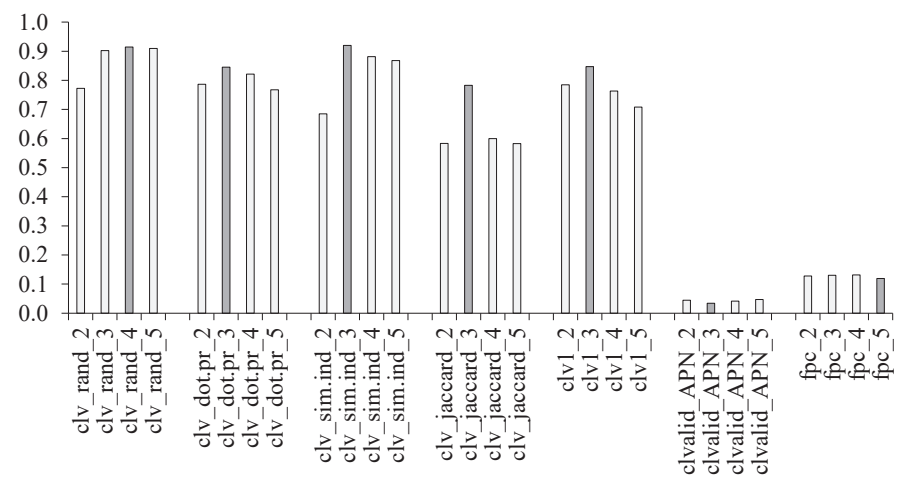

Figure 4. Values of stability measures for the Ward method (social domain) Source: own computations.

The results of clustering for the $k$-means and $k$-medoids method, according to the suggested number of groups indicated by most of the measures equal to three, are presented in Table 2. It can be seen that the results of these two partitioning methods are identical.

Table 2. Results of clustering for the partitioning method (social domain)

\begin{tabular}{|c|c|c|c|c|c|c|c|}
\hline \multicolumn{4}{|c|}{$k$-means } & \multicolumn{4}{|c|}{$k$-medoids } \\
\hline & group & & group & & group & & group \\
\hline Austria & 1 & Lithuania & 2 & Austria & 1 & Lithuania & 2 \\
\hline Belgium & 1 & Latvia & 2 & Belgium & 1 & Latvia & 2 \\
\hline Czech Republic & 1 & Poland & 2 & Czech Republic & 1 & Poland & 2 \\
\hline Germany & 1 & Romania & 2 & Germany & 1 & Romania & 2 \\
\hline Denmark & 1 & Estonia & 3 & Denmark & 1 & Estonia & 3 \\
\hline Finland & 1 & Spain & 3 & Finland & 1 & Spain & 3 \\
\hline France & 1 & Croatia & 3 & France & 1 & Croatia & 3 \\
\hline Luxembourg & 1 & Ireland & 3 & Luxembourg & 1 & Ireland & 3 \\
\hline the Netherlands & 1 & Italy & 3 & the Netherlands & 1 & Italy & 3 \\
\hline Sweden & 1 & Malta & 3 & Sweden & 1 & Malta & 3 \\
\hline Bulgaria & 2 & Portugal & 3 & Bulgaria & 2 & Portugal & 3 \\
\hline Cyprus & 2 & Slovenia & 3 & Cyprus & 2 & Slovenia & 3 \\
\hline Greece & 2 & Slovakia & 3 & Greece & 2 & Slovakia & 3 \\
\hline Hungary & 2 & Great Britain & 3 & Hungary & 2 & Great Britain & 3 \\
\hline
\end{tabular}

Source: own computations. 
In hierarchical methods, for average - the link method as the stable number of groups, most stability measures indicated four groups, while for the Ward method mainly three groups were suggested. The results for both methods are presented on figures 5 and 6 . The only difference between these two clusterings is that the group of countries: Belgium, the Netherlands, Luxembourg, Germany and Finland, which in the average - link method is a separate group, in the Ward method was joined to the larger group together with Denmark, Sweden, Czech Republic, Austria and France.

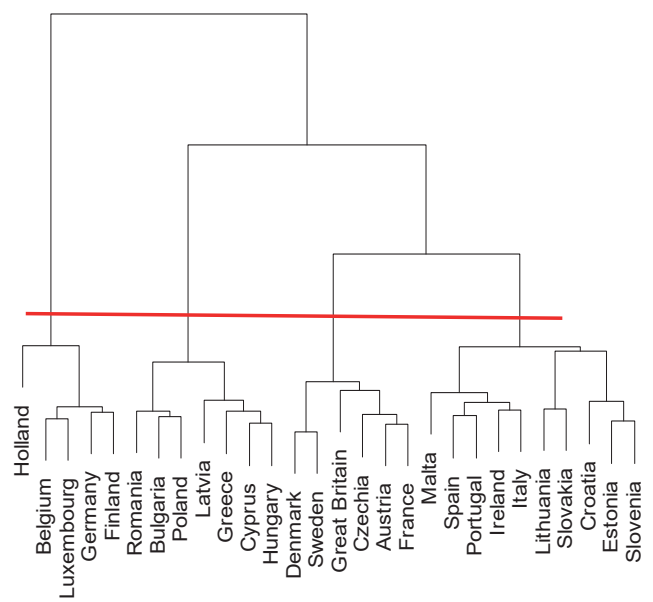

Figure 5. Results of clustering for the average method (social domain) Source: own computations.

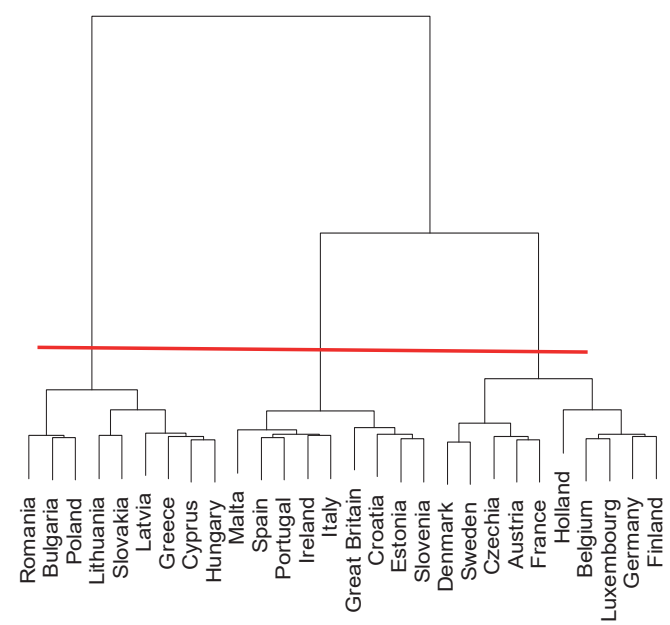

Figure 6. Results of clustering for the Ward method (social domain) 


\subsection{The economic domain}

For the partitioning method it can be noticed that most variants of the A. Ben-Hur and I. Guyon measure suggested two cluster for the $k$-means. The only exception is the variant based on the Rand index. For the $k$-medoids the measures were even more unanimous, six from seven methods of stability measure suggested the existence of two clusters. Again, the Y. Fang and J. Wang measure favor partitioning onto five clusters (for both the $k$-means and $k$-medoids method).

For the hierarchical method used within the economic domain stability measures are very consistent for all the method of stability measuring, showing the rightness of two clusters. The only exception again in the case of the Y. Fang and J. Wang stability measure that suggested the existence of five clusters.

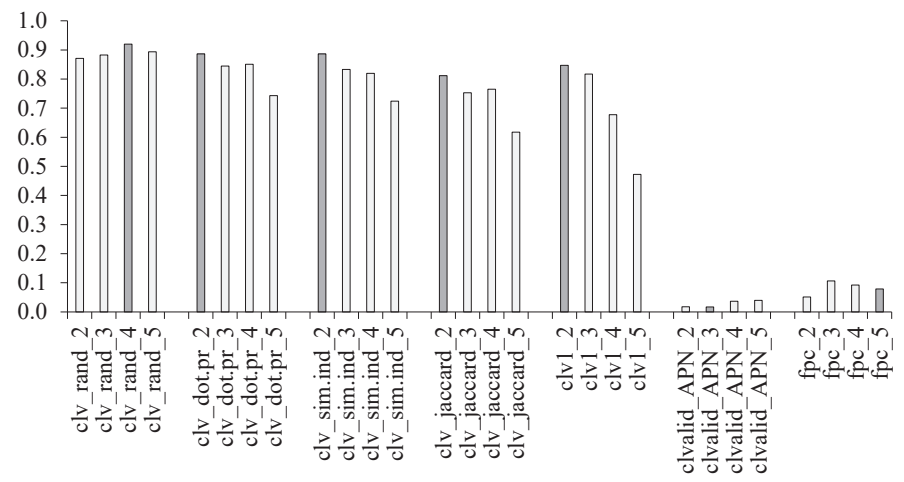

Figure 7. Values of stability measures for the $k$-means method (economic domain) Source: own computations.

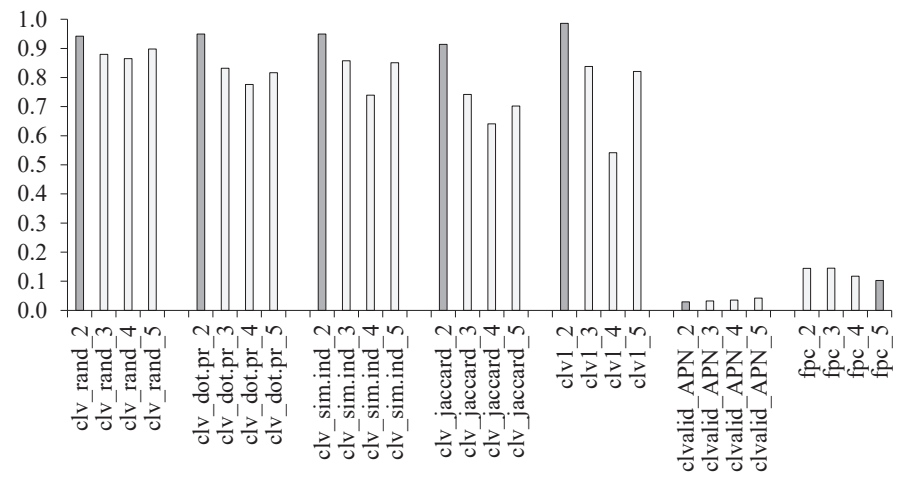

Figure 8 . Values of stability measures for the $k$-medoids method (economic domain) Source: own computations. 


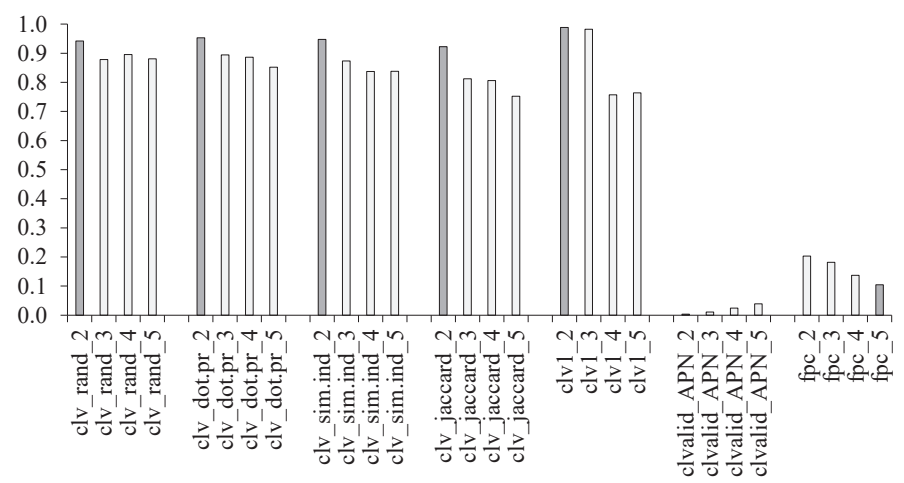

Figure 9. Values of stability measures for the average method (economic domain) Source: own computations.

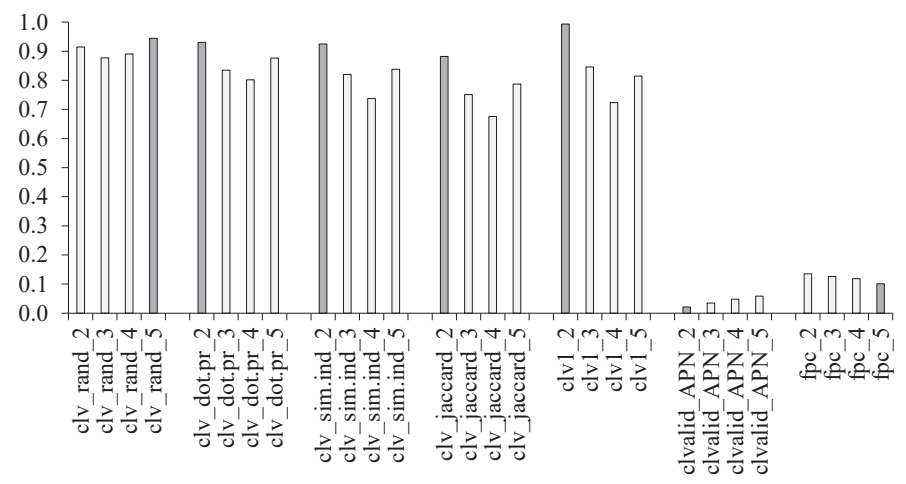

Figure 10. Values of stability measures for the Ward method (economic domain) Source: own computations.

However, regardless of the clustering method, it can again be seen that the Y. Fang and J. Wang method suggests the correct partitioning into the maximum number of considered groups.

Table 3 show results for partitioning methods, with $k=2$. Looking at the results one can conclude very similar groups in $k$-means and $k$-medoids clusterings. 
Table 3. Results of clustering for the partitioning method (economic domain)

\begin{tabular}{|l|c|l|c|l|c|l|c|}
\hline \multicolumn{3}{|c|}{$k$-means } & \multicolumn{5}{c|}{$k$-medoids } \\
\hline & group & & group & & group & & group \\
\hline Austria & 1 & France & 2 & Austria & 1 & Spain & 2 \\
\hline Germany & 1 & Croatia & 2 & Belgium & 1 & Croatia & 2 \\
\hline Denmark & 1 & Hungary & 2 & Germany & 1 & Hungary & 2 \\
\hline Finland & 1 & Ireland & 2 & Denmark & 1 & Ireland & 2 \\
\hline Luxembourg & 1 & Italy & 2 & Finland & 1 & Italy & 2 \\
\hline the Netherlands & 1 & Lithuania & 2 & France & 1 & Lithuania & 2 \\
\hline Sweden & 1 & Latvia & 2 & Luxembourg & 1 & Latvia & 2 \\
\hline Belgium & 2 & Malta & 2 & the Netherlands & 1 & Malta & 2 \\
\hline Bulgaria & 2 & Poland & 2 & Sweden & 1 & Poland & 2 \\
\hline Cyprus & 2 & Portugal & 2 & Bulgaria & 2 & Portugal & 2 \\
\hline Czech Republic & 2 & Romania & 2 & Cyprus & 2 & Romania & 2 \\
\hline Estonia & 2 & Slovenia & 2 & Czech Republic & 2 & Slovenia & 2 \\
\hline Greece & 2 & Slovakia & 2 & Estonia & 2 & Slovakia & 2 \\
\hline Spain & 2 & Great Britain & 2 & Greece & 2 & Great Britain & 2 \\
\hline
\end{tabular}

Source: own computations.

The results presented in figures 11 and 12, i.e. for the hierarchical methods with two clusters (indicated by most of the stability measures) reveals the same group membership regardless of the clustering method.

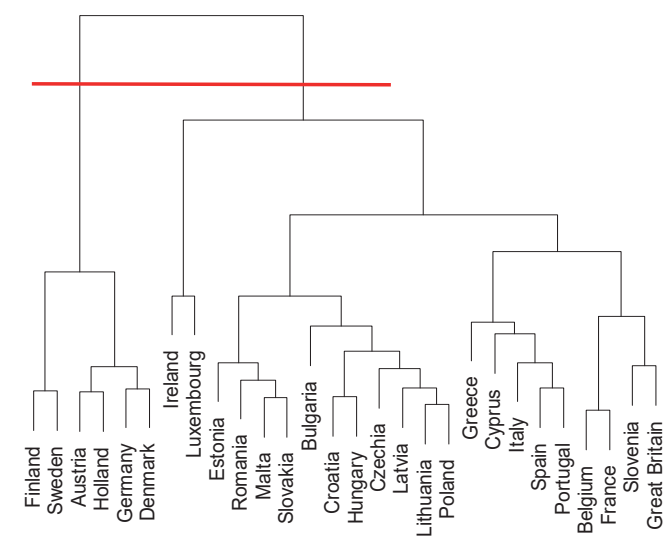

Figure 11. Results of clustering for the average method (economic domain)

Source: own computations. 


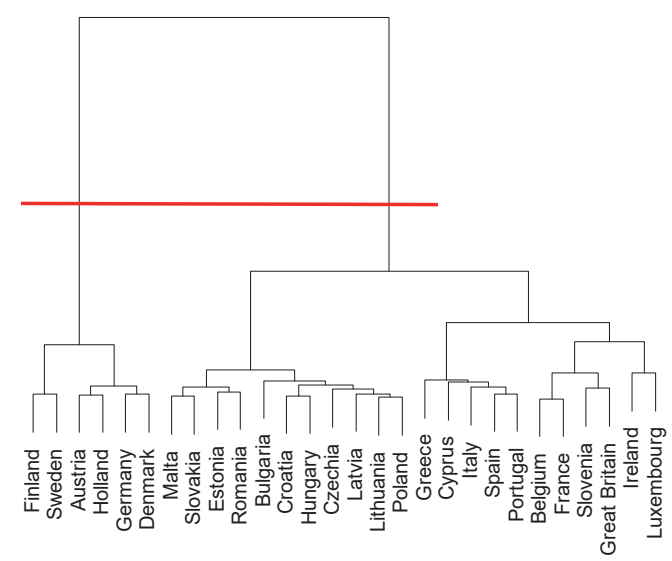

Figure 12. Results of clustering for the Ward method (economic domain) Source: own computations.

\subsection{The environmental domain}

A huge divergence of results as to the indications of the actual number of groups can be observed after applying the partitioning methods in the field of the environmental domain (figures 13-14). Only the Y. Fang and J. Wang method still consistently indicates as a correct division into 5 groups. Due to the huge discrepancy of results, the clusters produced by the $k$-means and $k$-medoids will not be presented later.

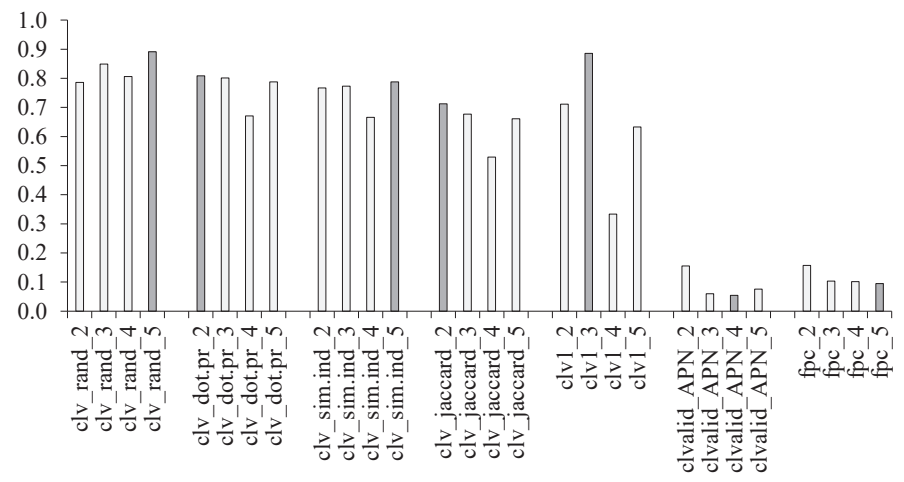

Figure 13. Values of stability measures for the $k$-means method (environmental domain) Source: own computations. 


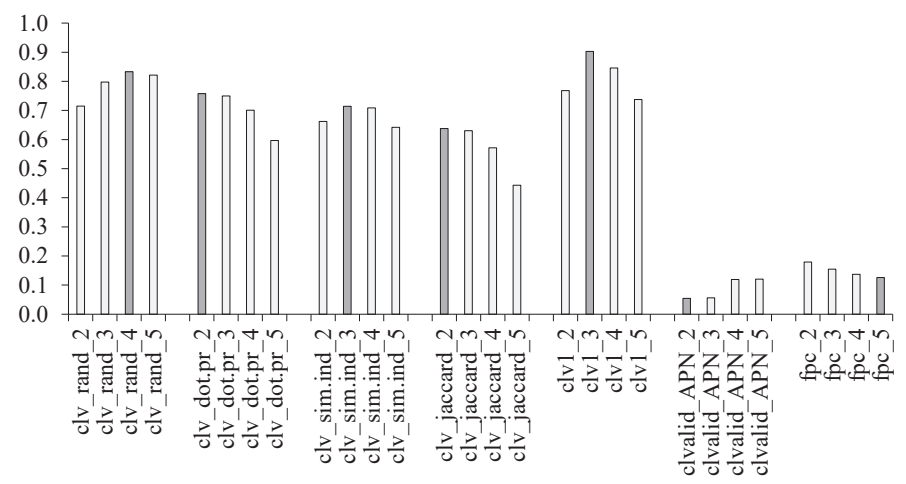

Figure 14. Values of stability measures for the $k$-medoids method (environmental domain) Source: own computations.

An easier situation exists for hierarchical methods used in this domain (figures 15-16). Most often the clustering in three groups was indicated as the most stable by the A. Ben-Hur and I. Guyon measure. The Brock et al. measure suggested two clusters, while the Y. Fang and J. Wang measure again suggested clustering into five groups.

Since for the $k$-means and $k$-medoids methods, stability measures indicated very different values of parameter $k$, therefore the presentation of grouping results using these methods was abandoned. Clustering by hierarchical methods, according to stability measures give three groups and the groups are identical (figures 17 and 18).

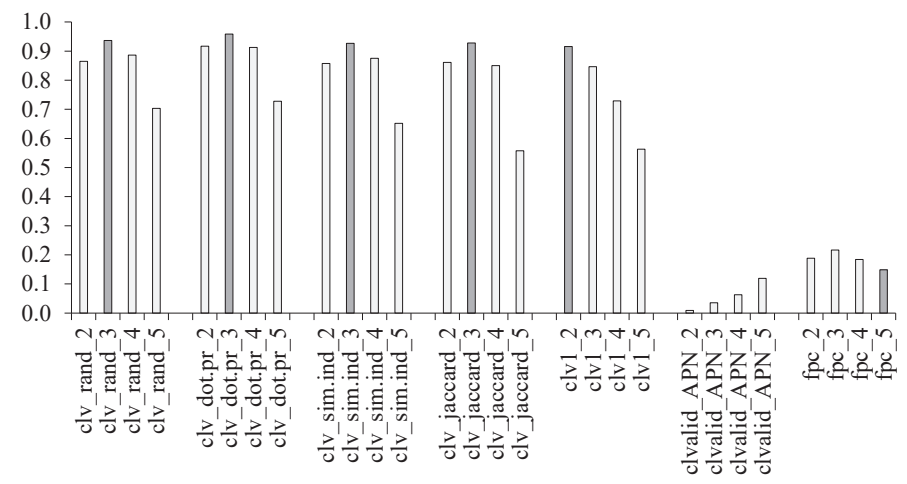

Figure 15. Values of stability measures for the average method (environmental domain) Source: own computations. 


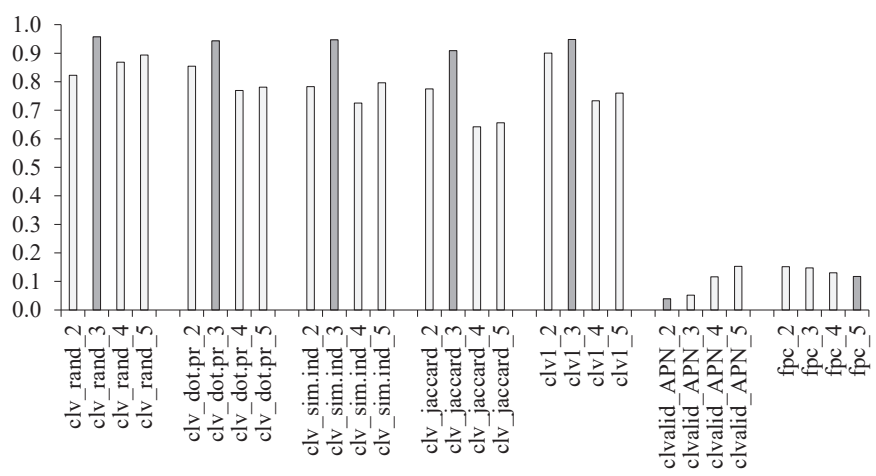

Figure 16. Values of stability measures for the Ward method (environmental domain) Source: own computations.

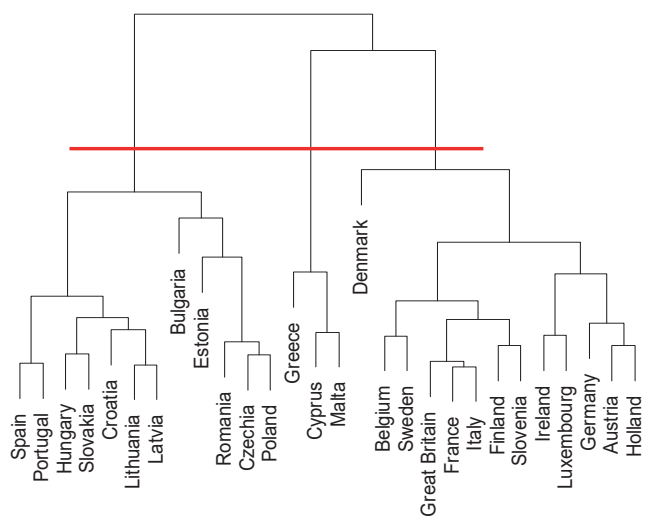

Figure 17. Results of clustering for the average method (environmental domain) Source: own computations.

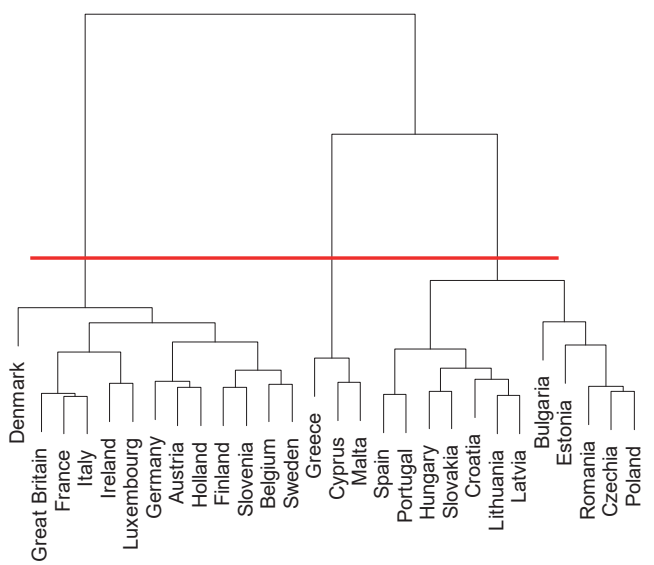

Figure 18. Results of clustering for the Ward method (environmental domain)

Source: own computations. 


\subsection{The institutional-political domain}

In this domain the clustering in two or five groups was indicated as most stable. Most often there were five groups, except for the group average - link, which mostly voted for two groups. This domain is also the only area where the Y. Fang and J. Wang measure of stability has proved the rightness of the division into two groups (specifically, for the $k$-medoids method).

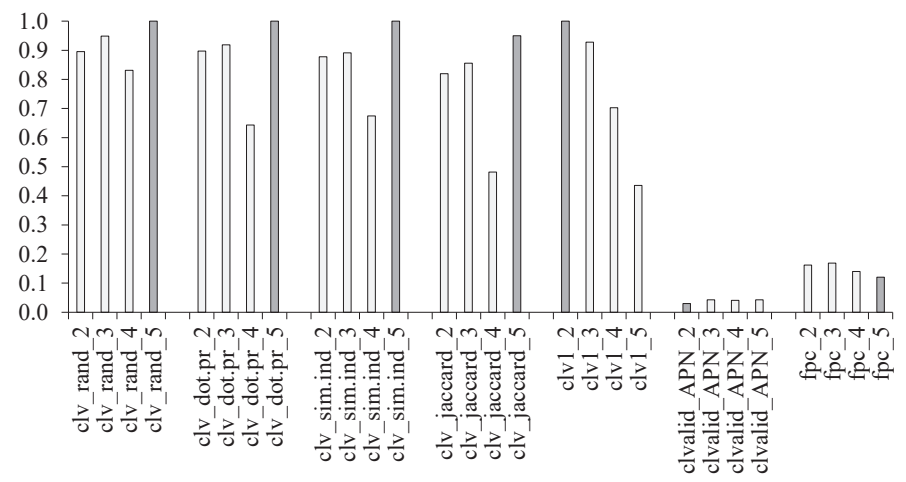

Figure 19. Values of stability measures for the $k$-means method (institutional-political domain) Source: own computations.

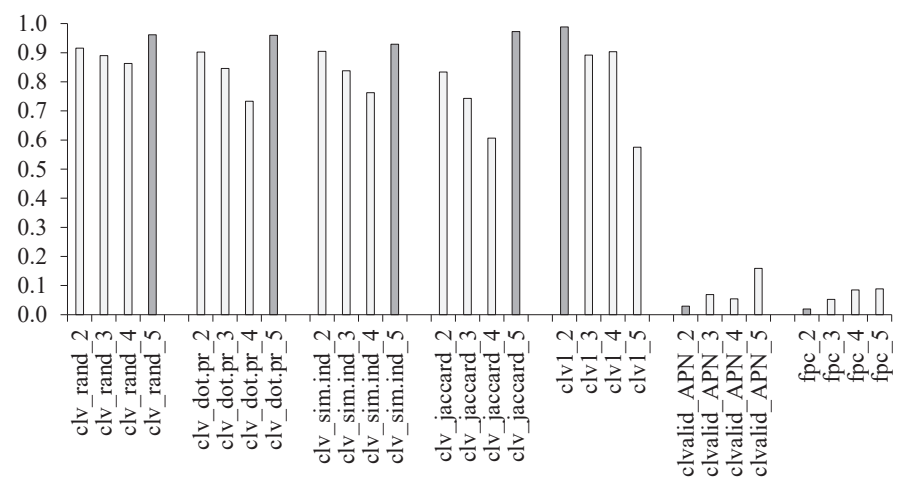

Figure 20. Values of stability measures for the $k$-medoids method (institutional-political domain) Source: own computations. 


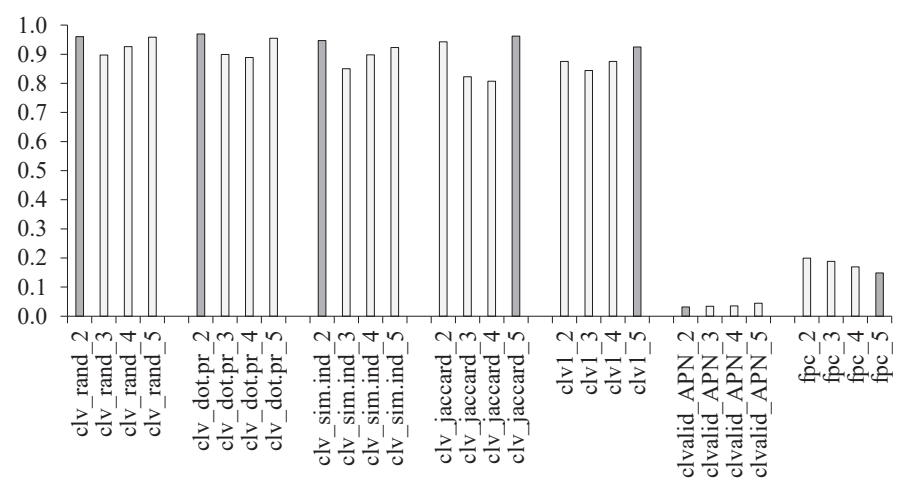

Figure 21. Values of stability measures for the average method (institutional-political domain) Source: own computations.

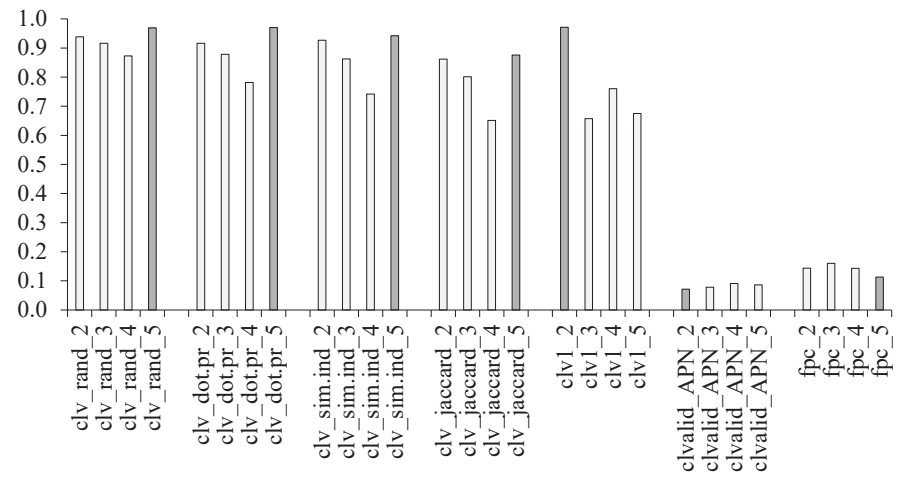

Figure 22. Values of stability measures for the Ward method (institutional-political domain) Source: own computations.

Looking at the results of clustering EU countries within the institutional-political domain (Table 4, figures 23 and 24), differences in the groups content can be noticed, with the parameter $k$ unchanged (this note applies to the $k$-means and $k$-medoids), but also quite large differences in the number of groups, suggested by stability measures (this remark applies to the hierarchical methods). 
Table 4. Results of clustering for the partitioning method (institutional-political domain)

\begin{tabular}{|c|c|c|c|c|c|c|c|}
\hline \multicolumn{4}{|c|}{$k$-means } & \multicolumn{4}{|c|}{$k$-medoids } \\
\hline & group & & group & & group & & group \\
\hline Austria & 1 & Romania & 2 & Austria & 1 & Malta & 2 \\
\hline Denmark & 1 & Slovenia & 2 & Belgium & 1 & Romania & 2 \\
\hline Estonia & 1 & Slovakia & 2 & Czech Republic & 1 & Slovakia & 2 \\
\hline Finland & 1 & Belgium & 3 & Greece & 1 & Germany & 3 \\
\hline Luxembourg & 1 & Spain & 3 & Ireland & 1 & the Netherlands & 3 \\
\hline Sweden & 1 & France & 3 & Lithuania & 1 & Great Britain & 3 \\
\hline Bulgaria & 2 & Italy & 3 & Poland & 1 & Denmark & 4 \\
\hline Cyprus & 2 & Germany & 4 & Portugal & 1 & Estonia & 4 \\
\hline Czech Republic & 2 & the Netherlands & 4 & Slovenia & 1 & Finland & 4 \\
\hline Greece & 2 & Great Britain & 4 & Bulgaria & 2 & Luxembourg & 4 \\
\hline Croatia & 2 & Hungary & 5 & Cyprus & 2 & Sweden & 4 \\
\hline Latvia & 2 & Ireland & 5 & Croatia & 2 & Spain & 5 \\
\hline Poland & 2 & Lithuania & 5 & Hungary & 2 & France & 5 \\
\hline Portugal & 2 & Malta & 5 & Latvia & 2 & Italy & 5 \\
\hline
\end{tabular}

Source: own computations.

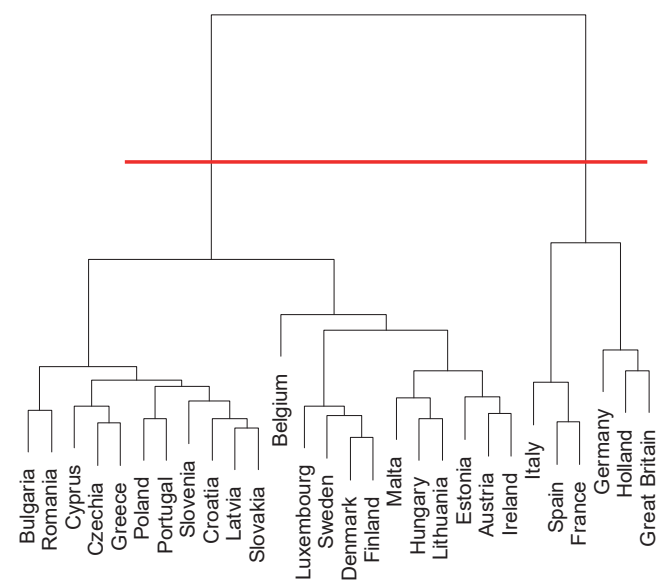

Figure 23. Results of clustering for the average method (institutional-political domain)

Source: own computations. 


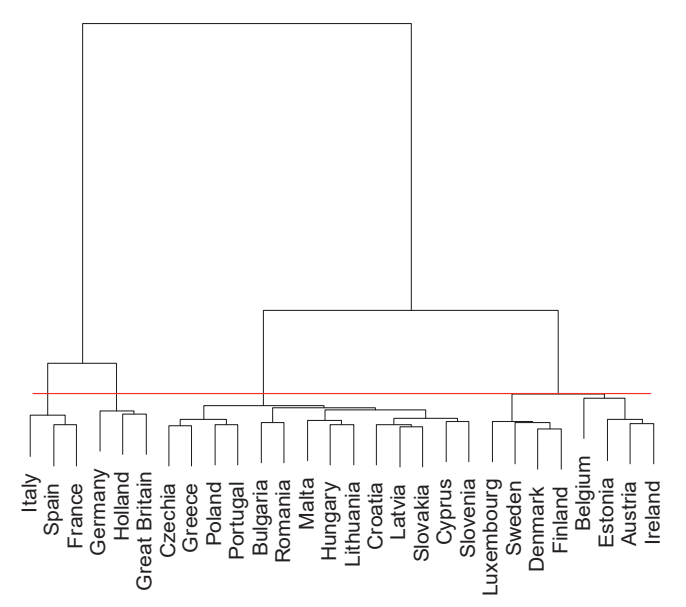

Figure 24. Results of clustering for the Ward method (institutional-political domain) Source: own computations.

\section{Conclusions}

Summing up this research, it should be noted that some of the stability measures are based on traditional indexes of clustering accuracy, e.g. the first presented measure of A. Ben-Hur and I. Guyon, which in their construction uses e.g. the Rand index or Jaccard index. But one can also find a measure of stability, which is a completely new proposal, e.g. proportion of non-overlap by Brock et al. or the measure of instability by Y. Fang and J. Wang which is based on empirical clustering distance.

Summing up the results of the empirical research, it should be noted first of all that the stability measures that were used in the study are not free from the basic disadvantage of traditionally used accuracy indices in taxonomy (e.g. Rand, silhouette), i.e. the decision on the number of clusters largely depends on the chosen stability method. Moreover, in the case of the A. Ben-Hur and I. Guyon measure, even the same concept of measuring stability, but using different accuracy indexes, can lead to different results in determining the value of $k$.

Another summary conclusion resulting from the conducted research is that the Y. Fang and J. Wang measure very often indicates the maximum considered value as the suggested number of clusters.

It seems that the next stage of research should be the confrontation of measures of clustering stability with traditionally used accuracy indexes. 
Due to the fact that in each of the considered domains (i.e. social, economic, environmental and institutional-political) stability measures indicated different values as the number of stable clusters, therefore it is impossible to clearly indicate Poland's cluster members in the EU in terms of sustainable development level. Identical clusters were found only by partitioning methods for social domain and hierarchical methods for the economic domain. The greatest difficulty in choosing a stable structure, and thus, Poland's place in the EU, was demonstrated by measures of stability in the field of environmental and institutional-political domains.

\section{References}

Ben-Hur, A., Guyon, I. (2003). Detecting stable clusters using principal component analysis. Methods in Molecular Biology. 224, 59-182.

Borys, T. (ed.) (2005). Wskaźniki zrównoważonego rozwoju. Warszawa-Białystok: Wydawnictwo Ekonomia i Środowisko. .

Borys, T. (2014). Wybrane problemy metodologii pomiaru nowego paradygmatu rozwoju - polskie doświadczenia. Optimum. Studia Ekonomiczne, 3 (69), 3-21.

Brock, G., Pihur, V., Datta, S., Datta, S. (2008). clValid: an R package for cluster validation. Journal of Statistical Software, 25 (4). Retrieved from: http://www.jstatsoft.org/v25/i04.

Fang, Y., Wang, J. (2012). Selection of the number of clusters via the bootstrap method. Computational Statistics and Data Analysis, 56, 468-477.

Henning, C. (2007). Cluster-wise assessment of cluster stability. Computational Statistics and Data Analysis, 52, 258-271.

Lord, E., Willems, M., Lapointe, F.J., Makarenkov, V. (2017). Using the stability of objects to determine the number of clusters in datasets. Information Sciences, 393, 29-46.

Lorek, E. (2011). Ekonomia zrównoważonego rozwoju w badaniach polskich i niemieckich. Studia Ekonomiczne, Zeszyty Naukowe Uniwersytetu Ekonomicznego w Katowicach, 90, 103-112.

Kronthaler, F. (2005). Economic capability of East German regions: Results of a cluster analysis. Regional Studies, 39 (6): 739-750.

Marino, V., Presti, L.L. (2019). Stay in touch! New insights into end-user attitudes towards engagement platforms. Journal of Consumer Marketing, 36, 772-783.

Repkine, A. (2012). How similar are the east asian economies? A cluster analysis perspective on economic cooperation in the region. Journal of International and Area Studies, 19 (1), $27-44$. 
Rozmus, D. (2017). Using R packages for comparison of cluster stability. Acta Universitatis Lodziensis Folia Oeconomica, 330 (4), 77-86.

Rozmus, D. (2019). Poziom zrównoważonego rozwoju w Polsce i krajach UE - analiza z zastosowaniem miar stabilności grupowania. Przeglad Statystyczny, LXVI (1), 84-93.

Shamir, O., Tishby, N. (2008). Cluster stability for finite samples. Advances in Neural Information Processing Systems, 20, 1297-1304.

Shubat, O., Bagirova, A, Makhabat, A., Ivlev, A. (2016). The use of cluster analysis for demographic policy development: evidence from Russia (pp. 159-165). 30th European Conference on Modelling and Simulation.

Simpach, O. (2013). Application of cluster analysis on the demographic development of municipalities in the districts of liberecky region (pp. 1390-1399). Conference Proceedings of the 7th International Days of Statistics and Economics.

Suzuki, R., Shimodaira, H. (2006). Pvclust: an R package for assessing the uncertainty in hierarchical clustering. Bioinformatics, 22 (12), 1540-1542.

Volkovich, Z., Barzily, Z., Toledano-Kitai, D., Avros, R. (2010). The Hotteling's metric as a cluster stability index. Computer Modelling and New Technologies, 14 (4), 65-72.

Wang, J. (2010). Consistent selection of the number of clusters via cross-validation. Biometrika, 97, 893-904. 